\title{
The role of endotoxin in critical illness myopathy and polyneuropathy
}

\author{
Jörg Ahrens • Martin Leuwer · Nilufar Foadi · \\ Gertrud Haeseler
}

Received: 1 July 2008/ Accepted: 26 February 2009/Published online: 22 March 2009

(C) Springer-Verlag 2009

\section{Comment}

Sirs: We read the article by Dr. Mohammadi and colleagues dealing with parameters that correlate with the severity of early stage critical illness polyneuropathy (CIP) with great interest [5]. The authors performed nerve conduction studies and electromyography in 20 consecutive patients with severe sepsis or septic shock from day 1 to day 14 after onset of sepsis. The essential finding was a reduction in the amplitude in the compound action potential of the median and/or peroneal nerve which was reduced in $75 \%$ of patients already at day 1 , and in $88 \%$ of patients at day 7. Remarkably, the reduction in the amplitude of the compound motor action potential correlated with the serum concentrations of endotoxin and interleukin-2-receptors. We have recently shown a direct interaction of endotoxin with heterologously expressed voltage-gated skeletal muscle sodium channels in vitro [4]. Endotoxin reduced sodium channel availability at depolarized membrane potentials during acute application of high concentrations $(\geq 50 \mathrm{ng} / \mathrm{ml})$ and after prolonged exposure $(1 \mathrm{~h})$ to a clinically relevant concentration $(300 \mathrm{pg} / \mathrm{ml})$. After $24 \mathrm{~h}$ of in vitro incubation with $300 \mathrm{pg} / \mathrm{ml}$ endotoxin, the reduction of

J. Ahrens $(\varangle) \cdot$ N. Foadi · G. Haeseler

Department of Anaesthesiology and Intensive care medicine; OE 8050, Hannover Medical School, Carl-Neuberg-Str. 1, 30625 Hannover, Germany

e-mail: ahrens.j@mh-hannover.de

\section{Leuwer}

Division of Clinical Sciences,

The University of Liverpool, Daulby Street,

Liverpool L69 3GA, UK sodium channel availability was irreversible and independent from the membrane potential.

In septic patients, CIP and critical illness myopathy (CIM) often coexist $[2,3]$, and the incidence in patients with sepsis or septic shock varies between $70 \%$ and $80 \%$ [1]. Taken together, the results of the clinical study performed by Dr. Mohammadi and colleagues, and our in vitro study on the interaction of endotoxin with voltage-gated sodium channels suggest that endotoxin might be a crucial factor in the development of neuromuscular sequelae of sepsis already at a very early stage after onset of sepsis. This highlights the need for development of anti-endotoxin strategies to prevent CIM and CIP.

\section{References}

1. Berek K, Margreiter J, Willeit J, Berek A, Schmutzhard E, Mutz NJ (1996) Polyneuropathies in critically ill patients: a prospective evaluation. Intensive Care Med 22:849-855

2. Bolton CF (2005) Neuromuscular manifestations of critical illness. Muscle Nerve 32:140-163

3. De Jonghe B, Sharshar T, Lefaucheur JP, Authier FJ, DurandZaleski I, Boussarsar M, Cerf C, Renaud E, Mesrati F, Carlet J, Raphael JC, Outin H, Bastuji-Garin S (2002) Paresis acquired in the intensive care unit: a prospective multicenter study. JAMA 288:2859-2867

4. Haeseler G, Foadi N, Wiegand E, Ahrens J, Krampfl K, Dengler R, Leuwer M (2008) Endotoxin reduces availability of voltage-gated human skeletal muscle sodium channels at depolarized membrane potentials. Crit Care Med 36:1239-1247

5. Mohammadi B, Schedel I, Graf K, Teiwes A, Hecker H, Haameijer B, Scheinichen D, Piepenbrock S, Dengler R, Bufler J (2008) Role of endotoxin in the pathogenesis of critical illness polyneuropathy. J Neurol 255:265-272 